\title{
CAN FULL OUTLINE OF UNRESPONSIVENESS SCORE (FOUR) REPLACE GLASGOW COMA SCALE (GCS) IN HEAD INJURY?: VALIDATION AT TERITIARY CARE CENTRE IN NEPAL
}

\author{
Prakash Kafle ${ }^{1}$, Mohan Raj Sharma², Sushil K Shilpakar ${ }^{2}$, Gopal Sedain ${ }^{3}$, Amit Pradhanang ${ }^{3}$,
}

Ram Kumar Shrestha ${ }^{4}$, Binod Rajbhandari ${ }^{5}$

\begin{abstract}
INTRODUCTION

Traumatic brain injury (TBI) is one of the major cause of severe disability and death world wide. The mortality rate in these patients largely depends on initial severity of trauma. In TBI, initial level of consciousness is most important prognostic indicator. The commonest scale is the Glasgow Coma Scale (GCS). Despite its widespread use, the GCS has some significant limitations, including variations in inter rater reliability and predictive validity. In order to overcome deficiencies of the GCS, an alternative scale called FOUR (Full Outline of Unresponsiveness score) has been developed and validated in several neurosurgical centers in North America. This study was an attempt to validate this score in Nepalese Setting. This study was carried out in the Department of Neurosurgery at Tribhuvan University Teaching Hospital, Kathmandu, Nepal. The main objective of the study was to compare the FOUR with GCS in predicting outcome in patients with Traumatic brain injury.
\end{abstract}

\section{MATERIAL AND METHODS}

Patients with moderate to severe head injury aged $\geq 16$ years admitted in the Department of Neurosurgery were eligible to participate in the study. The GCS and FOUR score were measured at the earliest possible time during admission by the single observer. Glasgow Outcome Scale (GOS) was measured at discharge and at 3 months follow up. Mortality was used as the primary outcome measure.

\section{RESULTS}

Total of 122 patients were included in the study. The mean age of the study population was $38.7 \pm 18$ years. Mean GCS score among survivors was higher than that among non -survivors which was statistically significant (10.9 \pm 2 vs. $6 \pm 1.12$ $(\mathrm{p}<0.001)$. Similarly mean FOUR score among survivors was significantly higher than that among non-survivors $(12.8 \pm$ 2.49 vs. $6.08 \pm 1.72(\mathrm{p}<0.001)$. The cut off point for GCS and FOUR score were $\leq 7 \mathrm{and} \leq 8$ respectively. The area under ROC curve for GCS for prediction of mortality was 0.975 (95\% I ; 0.947-1.000; $<<0.001)$ and for FOUR score was 0.981 (95\% CI; 0.960-1.000; $<0.001)$ suggesting good discrimination ability of both models. The overall sensitivity, specificity, positive predictive value and negative predictive values of GCS were $91.67 \%, 91.82 \%, 55 \%$ and $99 \%$ respectively while that for FOUR score were $100 \%, 91.82 \%, 57.1 \%$ and $100 \%$ respectively.

\section{CONCLUSION}

The outcome measurement of FOUR score was comparable with the GCS in traumatic brain injury and both the scores correlated well. 
KEYWORDS Traumatic brain injury, prognostic score score, Glasgow Coma Scale.

1. Lecturer, Department of Neurosurgery, Nobel Medical College \& Teaching Hospital, Biratnagar, Nepal.

2. Professor, Department of Neurosurgery, Tribhuvan University Teaching Hospital, Kathmandu Nepal.

3. Assistant professor, Department of Neurosurgery, Tribhuvan University Teaching Hospital Kathmandu Nepal

4. Consultant Neurosurgeon, Department of Neurosurgery, Om Hospital and Research centre, Kathmandu Nepal

5. Resident of Neurosurgery, Department of Neurosurgery, Tribhuvan University Teaching Hospital Kathmandu Nepal

\author{
For Correspondence: \\ Dr. Prakash Kafle \\ Lecturer \\ Department of Neurosurgery \\ Nobel Medical College and Teaching Hospital, \\ Biratnagar, Nepal \\ E-mail:prakashkaflee@gmail.com
}




\section{INTRODUCTION}

Traumatic brain injury (TBI) is the leading cause of death and disability worldwide. In the US alone, this type of injury causes 290,000 hospital admissions, 51,000 deaths, and 80,000 permanently disabled survivors ${ }^{1}$. Overall, $12 \%$ patients with TBI have severe disability and death ${ }^{2}$. Initial determination of injury in patients with TBI helps develop the basic guide to determine the outcome of trauma and treatment programs ${ }^{3}$. Considering the high mortality due to TBI as well as high costs of inpatient and long-term treatments, outcome prediction has long been a concern. ${ }^{4}$ Knowledge of medicallyaccepted diagnostic criteria and reliance on validated behavioral assessment scales are crucial for establishing accurate diagnosis, prognostic and management decisions (including end-of-life).

There is no objective measure of coma like temperature or blood pressure. Thus, for the assessment of the level of consciousness one has to rely on clinical scores. In recognition of these problems, various scoring scales have been proposed and validated. For examples, GCS (Glasgow Coma Scale), RAPS (The Rapid Acute Physiology Score) ${ }^{6}$, REMS (Rapid Emergency Medicine Score) ${ }^{7}$, APACHE (Acute Physiology and Chronic Health Evaluation) ${ }^{8}$, IHSS (In House Score System $)^{9}$, and so forth.

An ideal scoring system for evaluating coma should be: ${ }^{10}$

1. Easy to administer

2. Applicable to the greatest number of patients

3. Able to accurately assess level of consciousness,

4. Able to predict morbidity and mortality.

The most widely used coma scale is GCS, first described by Teasdale and Jennett in $1974^{5}$. The GCS was initially intended to assess level of consciousness after TBI in a neurosurgical intensive care unit ${ }^{5}$. The GCS has been broadly accepted as an instrument to classify the severity of TBI. It has become the gold standard against newer scales. GCS score ranges from 35 and has three components. Despite its widespread use, the GCS has some significant limitations, including variations in inter-rater reliability and predictive validity ${ }^{11}$. Other shortcomings of the GCS are inability to test verbal component in intubated patients, failure to grade breathing pattern and brainstem reflexes, and inability to detect subtle change in neurological examination. In order to overcome deficiencies of the GCS, an alternative scale was introduced by Wijdick et al. called FOUR (Full Outline of Unresponsiveness) score in the Mayo clinic ${ }^{12}$. This consists of four components (eye response, motor response, brainstem reflexes, and respiration), as well as the maximum score of each component. The FOUR Score is a 16-point scale (with potential scores ranging from 0 to 16). The FOUR score provides more neurological details; it identifies different stages of brain herniation; it facilitates the detection of lockedin syndrome and the vegetative state; and it does not include verbal response and thus may have a higher prognostic value for intubated patients. It not only includes the determination of eye opening, but also evaluates blinking and tracking of eyes. It has a broad spectrum of motor responses. It also considers the presence of abnormal breath rhythms and respiratory drive. Cheyne Stokes respiration and irregular breathing can represent bi-hemispheric or lower brainstem dysfunction of respiratory control. In intubated patients, over breathing the mechanical ventilator represents functioning respiratory centers. It doesn't have verbal component, so can be measured in intubated patients and those with aphasia, aphonia and vocal cord dysfunction/injury. It has been shown to have good inter-rater agreement. It also identifies vegetative versus minimally conscious states: Contrary to patients in vegetative/unresponsive state, those in minimally conscious state retain some capacity for cognitive, emotional, and pain processing $^{13}$. A score of 0 on the FOUR assumes the absence of brainstem reflexes and breathing and, therefore, helps to diagnose brain death. FOUR score is applicable for both traumatic ${ }^{1}$ and non-traumatic brain injury ${ }^{14}$. Construct and face validity of the scale have been established among neurologists, ${ }^{14}$ nurses, ${ }^{15}$ medical intensive care unit ${ }^{16}$, and emergency department staff ${ }^{17}$.

\section{MATERIAL AND METHODS}

This was a quantitative prospective observational study conducted at Department of Neurosurgery, Tribhuvan University Teaching Hospital, Institute of Medicine, Kathmandu, Nepal.All the patients aged more than 16 years of age with diagnosis of moderate to severe head injury were included in the present study over the period of 1year from October 2015 to September 2016. Exclusion criteria was post cardiopulmonary resuscitation (CPR) cases with return of spontaneous circulation (ROSC), with 'Do Not Resuscitate' status, who leave against medical advice, who are transferred to other hospitals.

As per the study protocol, in eligible patients who meet inclusion criteria, (post resuscitation if needed) GCS and FOUR scores was recorded at the time of admission. Each component of both scores was tested independently. If a patient was under sedative and/or neuromuscular blocking agent, the scores was taken at the earliest possible time of spontaneous awakening trial. Patients were managed with the standard head injury protocol and then discharged once they meet the discharge criteria. At the time of discharge the Glasgow Outcome Scale (GOS) scoring was done. All 
patients were followed up in 1, 4 and 12 weeks respectively. The GOS at 12 weeks follow up recorded and analyzed and correlated with GCS and FOUR score. No harm was caused because of the study. Every patient had the right to withdraw from the study, at any point of time.

\section{RESULTS}

During the study period, 155 patients were admitted with the diagnosis of moderate and severe head injury. Out of which 33 patients were excluded and final study population was 122 . These remaining 122 cases constitute the basis for this study as shown in diagram. The age range was $16-82$ years and mean age was $38.7 \pm 18$. The male population was ninety seven and female population was twenty five with the ratio of male to female 3.88:1. The patients admitted with moderate and severe head injuries were diagnosed as epidural hematoma(EDH), subdural hematoma(SDH), contusion, diffuse axonal injury (DAI), depressed Skull Fracture, traumatic subarachnoid hemorrhage and skull base injury. Mixed patterns were classified as others such as combination of EDH and SDH. The most common mode of injury in this study was road traffic accident followed by fall injury.

Mean GCS was $10.43 \pm 2.5$ among the study population and distribution of GCS score is as shown. Among them 88 (72.1 $\%$ ) had moderate severe injury (GCS 9-13) and 34(27.9\%) had severe head injury (GCS $<8)$. Mean of the FOUR score was $12.15 \pm 3.15$ among the 122 patients. Fifty nine underwent surgical treatment whereas sixty three were managed conservatively. Among them 12 patients died, making a mortality rate of $9.93 \%$. (12/122). Mean Duration of hospital stay was $9.7 \pm 8.3$ days. $43.4 \%$ (53) needed ICU and mean duration of ICU stay was $2.59 \pm 4.94$ days. We classified the Glasgow outcome score at discharge as dead, poor and good outcome. There is no significant difference as per age group and outcome. ( $p$ value 0.186 ) as shown in table 1.

Table 1. Relation between age and outcome

\begin{tabular}{|c|c|c|c|c|}
\hline \multirow{2}{*}{ Age Groups } & \multicolumn{3}{|c|}{ Outcome } & \multirow{2}{*}{ Total } \\
\cline { 2 - 4 } & Dead & $\begin{array}{c}\text { Poor } \\
\text { Outcome }\end{array}$ & $\begin{array}{c}\text { Good } \\
\text { Outcome }\end{array}$ & 24 \\
\hline up to 20 Years & 2 & 1 & 21 & 27 \\
\hline $21-30$ & 2 & 6 & 19 & 20 \\
\hline $31-40$ & 2 & 2 & 16 & 20 \\
\hline $41-50$ & 2 & 4 & 14 & 9 \\
\hline $51-60$ & 2 & 0 & 7 & 13 \\
\hline $61-70$ & 0 & 2 & 6 & 1 \\
\hline $71-80$ & 2 & 0 & 0 & 122 \\
\hline$>81$ & 0 & 1 & 94 & \\
\hline Total & 12 & 16 & & \\
\hline
\end{tabular}

At admission, mean FOUR Score and GCS score in the survivors were $12.8 \pm 2.49$ and $10.9 \pm 2$ respectively whereas in non-survivors were $6.08 \pm 1.72$ and $6 \pm 1.12$ respectively (Table 2) $\cdot p$ value was significant in both GCS and FOUR Score groups $(p<0.0001)$.

Table 2. Comparison between FOUR Score and GCS Score in Survivors

\begin{tabular}{|c|c|c|c|c|}
\hline & & $\begin{array}{c}\text { Number of } \\
\text { patients }\end{array}$ & Mean & $p$ value \\
\hline FOUR Score & Survivors & 110 & 12.8 & \multirow{2}{*}{$<0.0001$} \\
\cline { 2 - 4 } & Non-Survivors & 12 & 6.08 & \\
\hline \multirow{2}{*}{ GCS Score } & Survivors & 110 & 10.9 & \multirow{2}{*}{$<0.0001$} \\
\cline { 2 - 4 } & Non-Survivors & 12 & 6 & \\
\hline
\end{tabular}

Mean GCS and FOUR scores increased as the GOS at discharge increased which is tabulated in table 3 .

Table 3. Relation between GCS, FOUR score and GOS at discharge

\begin{tabular}{|c|c|c|c|}
\hline \multicolumn{2}{|c|}{ GOS at Discharge } & GCS & FOUR \\
\hline \multirow{2}{*}{ Dead } & Mean & 6 & 6 \\
\cline { 2 - 4 } & $\mathrm{N}$ & 12 & 12 \\
\hline Severe disability: & Mean & 7.6 & 9.13 \\
\cline { 2 - 4 } & $\mathrm{N}$ & 15 & 15 \\
\hline Moderate disability & Mean & 10.76 & 12.58 \\
\cline { 2 - 4 } & $\mathrm{N}$ & 46 & 46 \\
\hline Good recovery & Mean & 12.06 & 14.16 \\
\cline { 2 - 4 } & $\mathrm{N}$ & 49 & 49 \\
\hline Total & Mean & 10.42 & 12.15 \\
\cline { 2 - 4 } & $\mathrm{N}$ & 122 & 122 \\
\hline
\end{tabular}

The relation between GCS,FOUR score and GOS at 3 months is as shown in table no 4.

Table 4. Relation between GCS, FOUR score and GOS at 3 months

\begin{tabular}{|c|c|c|c|}
\hline \multicolumn{2}{|l|}{ GOS at 3 months } & GCS & $\begin{array}{c}\text { FOU } \\
\text { R }\end{array}$ \\
\hline \multirow{2}{*}{ Dead } & Mean & 6 & 6 \\
\cline { 2 - 4 } & $\mathrm{N}$ & 12 & 12 \\
\hline $\begin{array}{c}\text { Severe } \\
\text { disability: }\end{array}$ & Mean & 7.2 & 8.7 \\
\cline { 2 - 4 } $\begin{array}{c}\text { Moderate } \\
\text { disability }\end{array}$ & $\mathrm{N}$ & 7 & 7 \\
\cline { 2 - 4 } & $\mathrm{N}$ & 8.09 & 9.72 \\
\hline Good recovery & Mean & 11.5 & 13.5 \\
\cline { 2 - 4 } & $\mathrm{N}$ & 92 & 92 \\
\hline Total & Mean & 10.4 & 12.1 \\
& & 2 & 5 \\
\cline { 2 - 4 } & $\mathrm{N}$ & 122 & 122 \\
\hline
\end{tabular}




\section{Correlation between GCS and FOUR score}

The overall correlation between GCS and FOUR score was good, with Spearman's rho correlation coefficient of $0.946(p$ $<0.001)$. There was good correlation between GCS and GOS at discharge 0.698 and FOUR score and GOS at discharge 0.698. Also, there was good correlation between GCS and GOS at discharge 0.722 and FOUR score and GOS at 3 months 0.708. (Figure 1)

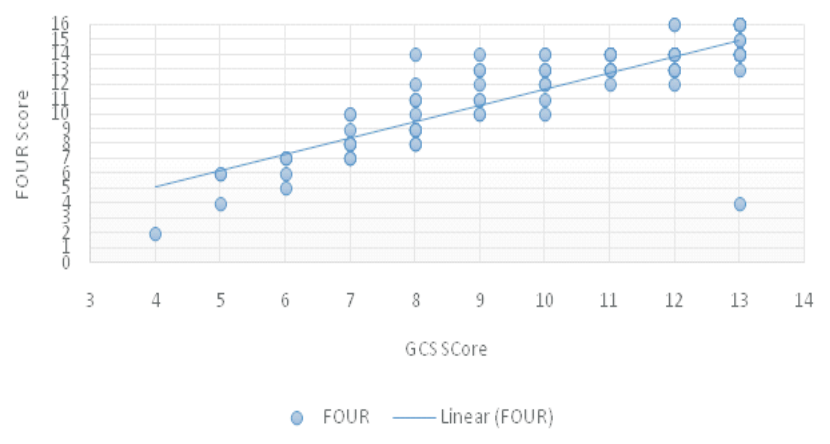

Figure 1. Correlation between GCS and FOUR score

The area under ROC curve for GCS for prediction of good outcome was 0.975 (95\% CI; 0.947-1.000; $<<0.001)$ and for FOUR score was 0.905 (95\% CI; 0.910-0.990; p<0.001) suggesting good discrimination ability of both models (figure 2)

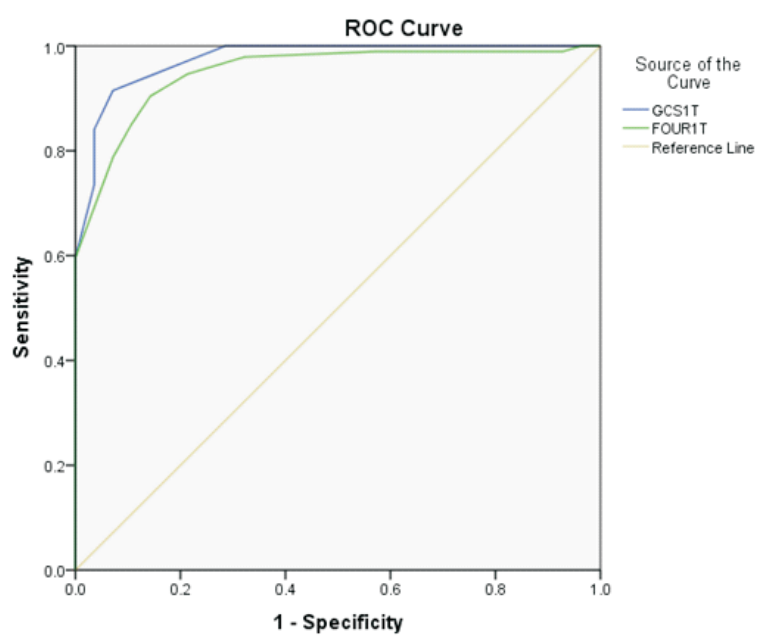

Figure 2. ROC curve for good prognosis

The area under ROC curve for GCS for prediction of mortality as $0.975(95 \% \mathrm{CI} ; 0.947-1.000 ; \mathrm{p}<0.001)$ and for FOUR score was 0.981 (95\% CI; 0.960-1.000; $<<0.001)$ suggesting good discrimination ability of both models (figure 3 ).

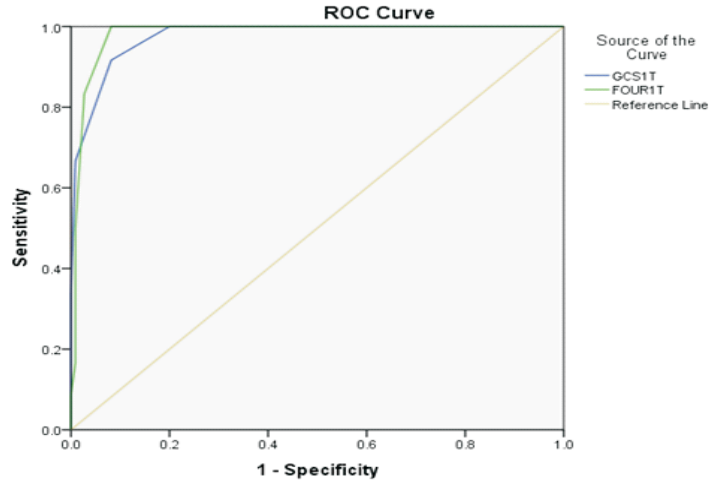

Figure 3. ROC curve for in hospital mortality

The best cut off point for both models is the corresponding models' score with maximum Youden Index (YI) value. At this point of maximum YI value, the best cut off point for GCS and FOUR score were $\leq 7$ and $\leq 8$ respectively. Of the 102 patients with GCS >7, there were one non-survivors and of the 20 patients with GCS $\leq 7$, there were 11 non-survivors, which was statistically significant $(\mathrm{p}<0.001)$ as shown below (table 5 and 6)

Table 5. Comparison of GCS of survivors and nonsurvivors above and below the cut off point

\begin{tabular}{|c|c|c|c|c|}
\hline GCS & Survival & Mortality & Total & $\mathrm{p}$ value \\
\hline${ }_{n n n n n}$ & 9 & 11 & 20 & $<0.001$ \\
\hline$>7$ & 101 & 1 & 102 & \\
\hline
\end{tabular}

Of the 21 patients with FOUR score $\leq 8$, there were 12 nonsurvivors and of the 101 patients with FOUR $>8$, there were zero non-survivors, which was statistically significant ( $\mathrm{p}<$ 0.001 ) as shown below.

Table 6. FOUR score of survivors and non-survivors above and below cutoff point

\begin{tabular}{|c|c|c|c|c|}
\hline FOUR & Survival & Mortality & Total & p value \\
\hline$\leq 8$ & 9 & 12 & 21 & \multirow{2}{*}{$<0.001$} \\
\hline$>8$ & 101 & 0 & 101 & \\
\hline
\end{tabular}

The overall sensitivity, specificity, positive predictive value and negative predictive value of GCS was $91.67 \%, 91.82 \%$, $55 \%$ and $99 \%$ respectively while that for FOUR score was $100 \%, 91.82 \%, 57.1 \%$ and $100 \%$ respectively. 


\section{DISCUSSION}

Defining the level of consciousness is a core clinical skill, which can be a challenge even for experienced physicians. The GCS, defined by Teasdale and Jennett ${ }^{5}$ in 1974, remains the most commonly used scoring system for LOC. Failure to assess the verbal score in intubated patients and the inability to test brainstem reflexes are shortcomings of GCS. In order to overcome deficiencies of the GCS, the FOUR score has been designed to provide further neurological details in coma patients, recognize certain unconscious states, and predict outcome.

Inter rater reliability of both the scores has been studied by various authors. Widjick et $\mathrm{al}^{12}$ found that the inter-rater reliability of the FOUR score and the GCS were of equivalent magnitude. This was remarkable because the raters had only minimal experience with the FOUR score. Validity of four score scale between trained and untrained evaluators, using the Spearman test, was obtained 0.90 which indicates that this instrument has high reliability between the evaluators. In a study done by Tadrishi et $\mathrm{al}^{31}$. Kevric et $\mathrm{al}^{18}$ also demonstrated that the inter-rater reliability for the FOUR Scale was greater than that of the GCS (FOUR: $\kappa=0.76, p<0.01$; GCS: $\kappa=0.59$, $p$ $<0.01)$. This study included all the cases admitted with diagnosis of moderate to severe head injury. Minimum age of the patient enrolled was 16 years and maximum age was 82 years with mean of $38.7 \pm 18$ years. Mcnett et al. ${ }^{32}$, Okasha et al. ${ }^{19}$ did their study on adult patient of traumatic brain injury. On the other hand, Iyer et al, ${ }^{16}$ Gujjar et al, ${ }^{33}$ Fisher et $\mathrm{al}^{34}$ and Bruno et $\mathrm{al}^{26}$ studied on medical patients whereas Kocaket $\mathrm{al}^{35}$ studied about the usefulness of FOUR score on acute stroke patient. In the present study, among 122 patients, there were 110 survivors $(90.16 \%)$. Remaining 12 patients $(9.83 \%)$ expired in hospital who were labeled non-survivors. Overall mortality observed in this study was $9.83 \%$ which were $21 \%$ in Widjicks et al ${ }^{12}$ study, $7.8 \%$ in Sadaka et $\mathrm{al}^{1}$ study and $10 \%$ in Büyükcamet $a^{24}$ study. Among 110 survivors, 16(14.5\%) had bad outcome and 94 (85.5\%) had good/favorable outcome at the hospital discharge. Receiver operating characteristic curves were estimated to compare prediction of in-hospital mortality between the two scales. In this study, the overall predictive performances of both the scores for in-hospital mortality were good with the area under ROC curve for GCS and FOUR scores of $0.975(95 \% \mathrm{CI} ; 0.947-1.000 ; \mathrm{p}<0.001)$ and $0.981(95 \% \mathrm{CI} ; 0.960-1.000 ; \mathrm{p}<0.001)$ respectively.

These findings are comparable with the findings of Widjicks et $\mathrm{al}^{12}$ study in which AUC was 0.89 for both scores and Sadakaet $\mathrm{al}^{1}$ study in which the AUC for in-hospital mortality was 0.89 and 0.93 respectively. Similarly the discriminating ability was good and comparative for both the scores in Fatih.et al ${ }^{24}$ study
(0.965 versus 0.975 for GCS and FOUR) and significantly lower in Eken et al. ${ }^{28}$ study (AUC 0.735 vs. 0.743 for GCS vs. FOUR).None of these studies showed significant difference which could be seen by analyzing the overlapped 95\% CI. However discriminating ability of FOUR score was significantly better in Okasha et $\mathrm{al}^{19}$ study over the GCS score (AUC 0.850 versus $0.796, p=0.025$ ). The difference in predictive ability of these scores may be due to inclusion of different patient types of population in different studies. The study population in the Bruno ${ }^{26}$ study included all traumatic and non-traumatic patients with brain injury who had GCS lower than 8 and tools were examined 1 month after injury but in our study examination of tools started in the first 24 hours of study and included only traumatic brain injury patients. Eken and colleagues ${ }^{28}$ included patients with mild neurologic signs in the normal levels of consciousness which comprised traumatic and non-traumatic samples. They followed patient's mortality for 3 months and poor outcome or 3-6 months. In our study, we recorded outcomes upto 3 months.

In this study, there was a good correlation between GCS and FOUR score, with Spearman's rho correlation coefficient of 0.946 ( $p<0.001$ ). This result was consistent with Widjicks et $\mathrm{al}^{12}$ study (Spearman's rho=0.92) and Bruno et $\mathrm{al}^{26}$ study (Spearman's rho $=0.81$ ).Moderate correlation is seen between GCS and FOUR with GOS at discharge with spearman's rho of 0.698 and 0.698 respectively. GCS ( 0.722$)$ showed slightly better correlation with GOS at 3 months than FOUR score( 0.698). Fatih et $\mathrm{al}^{24}$ study demonstrated better correlation of FOUR with the outcome (0.512 FOUR versus 0.489 GCS). The best Youden index was used to determine the best cut off point for survivors and non-survivors. Survivors and nonsurvivors were compared above and below the cutoff points. The best cut off point calculated from Youden index in our study was 7 for the GCS and 8 for FOUR scores. However this result was comparable with Widjicks et $\mathrm{l}^{12}$ study where the best cut off points were 7 and 9 respectively for GCS and FOUR score and not comparable with Akavipat et $\mathrm{al}^{23}$ study where the best cut off points were 10 and 14 for GCS and FOUR score respectively. The cut-off values in Eken et $\mathrm{al}^{28}$ study were 5 for the GCS and 9 for the FOUR Score in predicting mortality, but if the hospital mortality was used as the outcome measure; both the cut-off values for the GCS and FOUR Scores were found to be 4 . These differences may be as a result of the statistical techniques used in determining the cut-off values and the differences between the types of study populations. Wijdicks et al. ${ }^{12}$ used the maximum sum of sensitivity and specificity, which is similar to Youden Index (sensitivity+specificity1). However, Eken et al. ${ }^{28}$ used the positive likelihood ratio to determine the cut-off values.

In this study among 101 patients with FOUR score $>8,101$ 
were survivors and there was no non- survivor. And among 21 patients with FOUR score $\leq 8,12$ were non-survivors and 9 were survivors, the difference was statistically significant. Similarly, among 102 patients with GCS >7, 101 were survivor and 1 was non-survivor. And among 20 patients with GCS $\leq 7,11$ were non-survivors and 9 were survivors, the difference was statistically significant $(\mathrm{p}<0.001)$.

Mean GCS score among survivors was higher than that among non-survivorswhich was statistically significant (10.9 \pm 2 vs. $6 \pm 1.12(\mathrm{p}<0.001)$. Similarly mean FOUR score among survivors was significantly higher than that among nonsurvivors $(12.8 \pm 2.49$ vs. $6.08 \pm 1.72(p<0.001)$. This result was comparable with results from Jalali et $\mathrm{al}^{20}$ study in which mean GCS scores among survivors and non-survivors were $6.58 \pm 2.28$ and $4.62 \pm 2.094$, respectively and for FOUR score, they were $8.42 \pm 2.925$ and $4.7 \pm 3.471$, respectively. The results of our study was also consistent with the results of the studies by Widjicks et $\mathrm{al}^{12}$ and Bruno et $\mathrm{al}^{26}$ in which a low total GCS and FOUR scores were associated with poor outcomes. Even though the Modified Rankin Scale or Health-related Quality of Life is more accepted by many clinicians to evaluate outcome of neuro surgical patients but in this study, we discerningly applied the Glasgow Outcome Scale because the objective was focused on the mortality at discharge. Furthermore, we conducted and continued the evaluation until the date of discharge not the 3 month or 6-month mortality, in order to control for possible factors affecting the outcomes, such as physical rehabilitation, alternative treatment, and other modalities.

In this study sensitivity of FOUR score was better than GCS score ( $100 \%$ vs $91.67 \%$ ) whereas specificity ( 91.82 vs 91.82 $\%$ ), positive predictive value ( 55 vs $57.1 \%$ ) and negative predictive value ( 99 vs $100 \%$ ) of GCS and FOUR for prediction of the in-hospital mortality were almost similar. In the study of Wijdicks et $\mathrm{al}^{12}$, sensitivity, specificity and positive predictive value of GCS was $80 \%, 80 \%$ and $72 \%$ respectively while that for FOUR score was $75 \%, 76 \%$ and $72 \%$ respectively. Whereas in the study by Jalali et $\mathrm{al}^{20}$ the sensitivity,specificity and positive predictive value of GCS was $68 \%, 63 \%$ and $52 \%$ respectively while that for FOUR score was $68 \%, 77 \%$ and $63 \%$ respectively. That is FOUR score had better specificity and positive predictive value in terms of in hospital mortality prediction. Similarly, Phuping study $^{23}$ also showed better sensitivity, specificity and positive predictive value for GCS but better negative predictive for FOUR score. In addition to in hospitality mortality prediction, predictive abilities of this two scores have been compared for other outcomes like endotracheal intubation, length of ICU stay, 30 days mortality and 60 days mortality. Okasha and colleagues $^{19}$ studied on the predictive abilities of GCS and
FOUR scores in predicting the need of endotracheal intubation as one of the outcomes of traumatic brain injury. AUC for GCS was higher than AUC for the FOUR score (0.982 vs. 0.961). However, the difference between AUCs was not statistically significant $(\mathrm{p}=0.06)$. The optimal score to predict endotracheal intubation was 11 for the FOUR score (sensitivity $79 \%$; specificity $100 \%$ ) and 8 for the GCS (sensitivity $87 \%$; specificity $100 \%$ ).

Fatih and colleagues ${ }^{24}$ demonstrated that in predicting hospitalization of more than three days and poor outcome at discharge and after three months, the total GCS value was better than the total FOUR score, and further, in predicting hospital mortality, the total FOUR score was slightly better than the total GCS, but these differences were not significant. Also spearman correlation between hospitalization duration and GCS and FOUR score was poor, but moderate correlations were observed between both GCS and FOUR score and the GOS score at discharge, GOS score after three months and in-hospital mortality.

\section{CONCLUSION}

The FOUR score is as effective as but not superior to GCS in predicting outcomes in the patients with TBI. Further multi center studies involving larger population of various disease categories may be helpful to justify the result of the study.

\section{REFERENCES}

1. Sadaka F, Patel D, Lakshmanan R. The FOUR score predicts outcome in patients after traumatic brain injury. Neurocrit Care. 2012;16(1):95-101.

2. Fleminger S, Ponsford J. Long term outcome after traumatic brain injury. BMJ. 2005;331(7530):1419-20.

3. Valadka AB NR. Emergency room management of the head injury patient. . Narayan R PJ, editor. Newyork: Mc Graw-Hill; 1996.

4. Noorizad S TH MM, . Causes of Mortality and Morbidity in a Neurosurgery ICU in Kashan 1999-2001. Feyz. 2005(9):15-20.

5. Teasdale G, Jennett B. Assessment of coma and impaired consciousness. A practical scale. Lancet. 1974;2(7872):81-4.

6. Rhee KJ, Fisher CJ, Jr., Willitis NH. The Rapid Acute Physiology Score. Am J Emerg Med. 1987;5(4):278-82.

7. Olsson T, Terent A, Lind L. Rapid Emergency Medicine Score can predict long-term mortality in nonsurgical emergency department patients. Acad Emerg Med. 2004;11(10):1008-13.

8. Knaus WA, Zimmerman JE, Wagner DP, Draper EA, Lawrence DE. APACHE-acute physiology and chronic health evaluation: a physiologically based classification system. Crit Care Med. 1981;9(8):591-7. 
9. Maheswaran M, Adnan WA, Ahmad R, Ab Rahman NH, Naing NN, Abdullah J. The use of an In House Scoring System Scale versus Glasgow Coma Scale in non-traumatic altered states of consciousness patients: can it be used for triaging patients in Southeast Asian developing countries? Southeast Asian J Trop Med Public Health. 2007;38(6):1126-40.

10. Kornbluth J, Bhardwaj A. Evaluation of coma: a critical appraisal of popular scoring systems. Neurocrit Care. 2011;14(1):134-43.

11. Cohen J. Interrater reliability and predictive validity of the FOUR score coma scale in a pediatric population. J Neurosci Nurs. 2009;41(5):261-7; quiz 8-9.

12. Wijdicks EF, Bamlet WR, Maramattom BV, Manno EM, McClelland RL. Validation of a new coma scale: The FOUR score. Ann Neurol. 2005;58(4):585-93.

13. Schiff ND, Rodriguez-Moreno D, Kamal A, Kim KH, Giacino JT, Plum F, et al. fMRI reveals large-scale network activation in minimally conscious patients. Neurology. 2005;64(3):514-23.

14. Idrovo L, Fuentes B, Medina J, Gabaldon L, Ruiz-Ares G, Abenza MJ, et al. Validation of the FOUR Score (Spanish Version) in acute stroke: an interobserver variability study. Eur Neurol. 2010;63(6):364-9.

15. Wolf CA, Wijdicks EF, Bamlet WR, McClelland RL. Further validation of the FOUR score coma scale by intensive care nurses. Mayo Clin Proc. 2007;82(4):435-8.

16. Iyer VN, Mandrekar JN, Danielson RD, Zubkov AY, Elmer JL, Wijdicks EF. Validity of the FOUR score coma scale in the medical intensive care unit. Mayo Clin Proc. 2009;84(8):694701.

17. Stead LG, Wijdicks EF, Bhagra A, Kashyap R, Bellolio MF, Nash DL, et al. Validation of a new coma scale, the FOUR score, in the emergency department. Neurocrit Care. 2009;10(1):50-4.

18. Kevric J, Jelinek GA, Knott J, Weiland TJ. Validation of the Full Outline of Unresponsiveness (FOUR) Scale for conscious state in the emergency department: comparison against the Glasgow Coma Scale. Emerg Med J. 2011;28(6):486-90.

19. Okasha AS, Fayed AM, Saleh AS. The FOUR score predicts mortality, endotracheal intubation and ICU length of stay after traumatic brain injury. Neurocrit Care. 2014;21(3):496-504.

20. Jalali R, Rezaei M. A comparison of the glasgow coma scale score with full outline of unresponsiveness scale to predict patients' traumatic brain injury outcomes in intensive care units. Crit Care Res Pract. 2014;2014:289803.

21. Gorji MA, Hoseini SH, Gholipur A, Mohammadpur RA. A comparison of the diagnostic power of the Full Outline of Unresponsiveness scale and the Glasgow coma scale in the discharge outcome prediction of patients with traumatic brain injury admitted to the intensive care unit. Saudi J Anaesth. 2014;8(2):193-7.

22. Bordini AL, Luiz TF, Fernandes M, Arruda WO, Teive HA.
Coma scales: a historical review. Arq Neuropsiquiatr. 2010;68 (6):930-7.

23. Akavipat P. Endorsement of the FOUR score for consciousness assessment in neurosurgical patients. Neurol Med Chir (Tokyo). 2009;49(12):565-71.

24. Buyukcam F, Kaya U, Karakilic ME, Cavus UY, Turan Sonmez F, Odabas O. Predicting the outcome in children with head trauma: comparison of FOUR score and Glasgow Coma Scale. Ulus Travma Acil Cerrahi Derg. 2012;18(6):469-73.

25. Chen B, Grothe C, Schaller K. Validation of a new neurological score (FOUR Score) in the assessment of neurosurgical patients with severely impaired consciousness. Acta Neurochir (Wien). 2013;155(11):2133-9; discussion 9

26. Bruno MA, Ledoux D, Lambermont B, Damas F, Schnakers C, Vanhaudenhuyse A, et al. Comparison of the Full Outline of UnResponsiveness and Glasgow Liege Scale/Glasgow Coma Scale in an intensive care unit population. Neurocrit Care. 2011;15(3):447-53.

27. Holdgate A, Ching N, Angonese L. Variability in agreement between physicians and nurses when measuring the Glasgow Coma Scale in the emergency department limits its clinical usefulness. Emerg Med Australas. 2006;18(4):379-84.

28. Eken C, Kartal M, Bacanli A, Eray O. Comparison of the Full Outline of Unresponsiveness Score Coma Scale and the Glasgow Coma Scale in an emergency setting population. Eur J Emerg Med. 2009;16(1):29-36.

29. Connor RJ. Sample size for testing differences in proportions for the paired-sample design. Biometrics. 1987;43(1):207-11.

30. Jennett B, Bond M. Assessment of outcome after severe brain damage. Lancet. 1975;1(7905):480-4.

31. Tadrisi SD BN, Ebadi A, Madani s. Validity and reliability of coma scale (four score) in adult patient hospitalized in Critical Care Units Iran J Crit Care Nurs. 2012;5(2):8.

32. McNett M. A review of the predictive ability of Glasgow Coma Scale scores in head-injured patients. J Neurosci Nurs. 2007;39(2):68-75

33. Gujjar AR, Jacob PC, Nandhagopal R, Ganguly SS, Obaidy A Al-Asmi AR. Full Outline of UnResponsiveness score and Glasgow Coma Scale in medical patients with altered sensorium: interrater reliability and relation to outcome. J Crit Care. 2013;28(3):316 e1-8.

34. Fischer M, Ruegg S, Czaplinski A, Strohmeier M, Lehmann A, Tschan F, et al. Inter-rater reliability of the Full Outline of UnResponsiveness score and the Glasgow Coma Scale in critically ill patients: a prospective observational study. Crit Care. 2010;14(2):R64

35. Kocak Y, Ozturk S, Ege F, Ekmekci H. A useful new coma scale in acute stroke patients: FOUR score. Anaesth Intensive Care. 2012;40(1):131-6. 